\title{
Pilares necesarios para una descentralización autónoma sin cooptación del poder central: reflexiones para el proceso descentralizador chileno
}

\author{
Esteban Valenzuela \\ Universidad Alberto Hurtado / Departamento de Ciencia Política y Relaciones Internacionales \\ Chile \\ Fabián Pressacco \\ Universidad Alberto Hurtado / Departamento de Ciencia Política y Relaciones Internacionales \\ Chile \\ Ignacio Cienfuegos \\ Universidad Alberto Hurtado / Departamento de Ciencia Política y Relaciones Internacionales \\ Chile \\ Francesco Penaglia \\ Universidad Alberto Hurtado / Departamento de Ciencia Política y Relaciones Internacionales \\ Chile
}

\begin{abstract}
El debate sobre la descentralización en Chile ha tomado un nuevo impulso de demandas a través de diversas acciones colectivas regionalistas desarrolladas desde el año 2011, las que han establecido un "nuevo ciclo" marcado por redefiniciones de las relaciones entre Estado y sociedad. Este nuevo periodo se ha caracterizado por un fuerte debate político, el que ha enfrentado a distintas posiciones e intereses en torno a cómo lograr una descentralización que permita un doble virtuosismo: desarrollar grados crecientes de autonomía evitando el caudillismo y la captura de los entes subnacionales por grupos y mafias locales, a la vez que generar un proceso descentralizador que evite la cooptación y control desde el poder central. Problematizando en torno a este último punto, el presente artículo es una investigación descriptiva-exploratoria, con énfasis en lo teórico, que busca identificar dimensiones de éxito de una descentralización no cooptativa, que sirvan como insumo al proceso chileno. Para ello se concluye que los tres pilares fundamentales para alcanzar una descentralización autónoma sin cooptación del poder central son el fortalecimiento y autonomía financiera, la participación y democratización territorial y un proceso de institucionalización.
\end{abstract}

Palabras clave: descentralización; América Latina; municipalismo; cooptación; Chile.

DOI: http://dx.doi.org/10.1590/0034-7612137403

Artículo enviado en 15 jul. 2014 y aprobado en 24 mar. 2015.

(c) (1)

El artículo es parte de la investigación FONDECYT 1150684 sobre Movimientos Regionalistas y Ciclo de reformas en Chile. 


\begin{abstract}
Pilares necessários para a descentralização autônoma sem cooptação do poder central: explorando o processo de descentralização do Chile
\end{abstract}

O debate sobre a descentralização no Chile tomou um novo impulso por meio de diversas ações coletivas regionalistas desenvolvidas a partir do ano 2011, estabelecendo um "novo ciclo" acentuado pelas redefinições da relação entre o Estado e a sociedade. Esse novo período se caracteriza por um forte debate político em que há diversos posicionamentos e interesses em torno de como alcançar uma descentralização que signifique um virtuosismo duplo: desenvolver capacidades e graus crescentes de autonomia evitando os caudilhismos e a captura dos entes subnacionais pelos grupos e máfias locais, assim como gerar um processo descentralizador que evite a cooptação e o controle do poder central. Problematizando este último aspecto, o presente artigo é uma pesquisa descritiva-exploratória, com ênfase teórica, que pretende identificar dimensões exitosas de uma descentralização não cooptada, que sirva de insumo ao processo chileno. Conclui-se que os três pilares fundamentais para lograr isso são: fortalecimento e autonomia financeira, participação e democratização territorial e um processo de institucionalização.

Palavras-chave: descentralização; América Latina; municipalismo; cooptação; Chile.

Necessary pillars for autonomous decentralization without cooptation of the central power: exploring the Chilean process of decentralization

The debate on decentralization in Chile has taken a new impulse, mainly through the demands of many regionalist collective actions that took place since 2011. These social movements have established a "new cycle", redefining, at some point, the relations between state and society. This period has confronted different positions on how to achieve decentralization that should accomplish two important objectives: developing the necessary autonomy and competences that would avoid the capture of subnational entities by local mafias and, at the same time, generate a decentralization process that prevent cooptation and control from the central government. Therefore, this article is an exploratory-descriptive research based on theory, which seeks to identify the key elements of success for a non-cooptative decentralization process in Chile. In that sense, we conclude the main three central pillars for this purpose are: strengthening and financial autonomy; participation and territorial democratization; and the process of institutionalization.

KeYwords: decentralization; Latin America; municipalities; cooptation; Chile.

\title{
1. Introducción
}

En Chile ha predominado un régimen centralista ${ }^{1}$ desde el triunfo conservador de Portales en 1830, quien "a sangre y fuego" se impuso ante federalistas y liberales (Villalobos, 1989). Esta construcción estatal centralista y desde arriba (Véliz, 1984; Góngora, 1981), ha debido sor-

\footnotetext{
${ }^{1}$ Caracterizado entre otras cosas la mantención de control regional y local tanto desde facultades legales y dependencia financiera. Chile es uno de los pocos casos en la OCDE y Latinoamérica, en donde las autoridades regionales no son elegidas democráticamente, sino delegadas desde el poder central, factor que se suma a un débil gasto subnacional y bajo nivel de potestades y competencias.
} 
tear guerras civiles en el decenio de 1850-1860 y periodos conflictivos en la década de 1930 (Penaglia y Valenzuela, 2014). La última gran crisis ha ocurrido el año 2011, cuando diversas regiones se levantaron en protestas contra el centralismo destacando diversos movimientos sociales como el de Calama, Aysén, Magallanes, Tocopilla, Quellón, Freirina, entre otros. A partir de entonces, la agenda pública y gubernamental se ha abierto a la discusión sobre reformas descentralizadoras, siendo el primer hito la creación de la Comisión Asesora Presidencial en Descentralización y Desarrollo Regional en abril de 2014.

Dando cuenta de un contexto descentralizador en Chile, el artículo busca indagar sobre los aspectos claves de un proceso exitoso, teniendo como principal premisa que existen dos formas de descentralización: una ligada a fortalecer las capacidades locales y la autonomía; y otro que mantiene las estructuras centralistas y crea condiciones para la existencia de mecanismos de cooptación.

Este último elemento, es uno de los principales obstaculizadores de un proceso descentralizador. Las investigaciones sobre cooptación, desde una visión clásica, se han enfocado en el análisis de prácticas clientelares centradas en el conocimiento de la cultura política expresada en una relación mercantil entre el poder político y el ciudadano: obtención de beneficios como el acceso a un subsidio, puesto de trabajo, vacante en una escuela, atención más oportuna, recursos económicos, reconocimiento, entre otros; a cambio de respaldo político en diferentes grados (desde el voto hasta respaldos más explícitos). Desde esta perspectiva, el clientelismo es una modalidad de cooptación de la voluntad popular desde el Estado, orientada a instrumentalizarla por la vía de debilitar la autonomía de los sujetos en la definición de sus opciones y la cultura democrática. ${ }^{2}$

Sin embargo, más allá de esta noción clásica de cooptación referida a la relación entre el poder político y la ciudadanía, la cooptación puede manifestarse en el plano intra-institucional en las relaciones intergubernamentales, en donde el poder central dispone de un conjunto de recursos que permiten restringir la autonomía de los poderes subnacionales y la ciudadanía local, desde ese plano limitar las posibilidades de cooptación pasa a ser un elemento clave a la hora de proyectar un proceso descentralizador exitoso.

\section{Metodología}

Al respecto, debemos señalar que el presente artículo da cuenta de un diseño se investigación explotario, el que busca responder una pregunta esencial asociada a: ¿cuáles son los pilares o dimensiones centrales para una descentralización efectiva y autónoma que restringa la capaci-

\footnotetext{
${ }^{2}$ Esto ocurre al menos por tres razones: a) Reemplaza la perspectiva de derechos por otra de carácter instrumental en donde el acceso a bienes públicos depende de la buena voluntad del gobierno de turno; b) refuerza la capacidad de control del poder gubernamental fortaleciendo la eficiencia de los mecanismos de que dispone para lograr la adhesión de la ciudadanía; c) debilita la libertad de expresión y la capacidad de definir preferencias por parte de la ciudadanía.
} 
dad cooptadora del poder central en las regiones? Dicha pregunta de investigación entonces, será respondida de manera deductiva, indagando teóricamente en los aspectos político financieros de la descentralización, discutiendo sobre la importancia y complejidad de un proceso de participación y rendición de cuentas, así como explorando en la pertinencia de contar con mecanismos institucionalizados de control y coordinación local. En este sentido, en una siguiente etapa de investigación empírica, el modelo teórico propuesto, pudiese ser analizado en profundidad, evaluando de manera inductiva, las potenciales desviaciones a partir del modelo teórico propuesto (Blalock, 1982).

La anterior opción metodológica, puede ser justificada en función de la inexistencia de investigación sistemática, así como teoría disponible que explique el fenómeno estudiado (descentralización sin cooptación) (Hox y De Jong-Gierveld, 1990). De esta manera, el principal objetivo de esta investigación es el de indagar teóricamente en un modelo de descentralización sin cooptación basado en la interacción sistémica de tres pilares; autonomía político-financiera, institucionalización y participación con rendición de cuentas, validando luego esta proposición en futuras investigaciones donde identifiquemos posibles relaciones entre estas dimensiones, así intentando caracterizar procesos descentralizadores a nivel latinoamericano donde las variables propuestas puedan operacionalizarse y explicarse bajo distintas condiciones.

En cuanto a las limitaciones de este estudio, es decir, aspectos que ponen restricciones en términos de posibles generalizaciones o conclusiones, debemos insistir en el carácter exploratorio de nuestro diseño de investigación. De esta manera, como hemos señalado, un estudio como este ofrece una primera aproximación al fenómeno estudiado, en este caso, reflexionar sobre los posibles pilares para una descentralización sin cooptación. En este sentido, nuestro artículo no pretende profundizar sobre dichos pilares, establecer relaciones, determinar condiciones o variables que controlen su ocurrencia, así como explicaciones sobre diversos contextos en que pudelemos observarlos, sino que intenta solamente identificar teóricamente estos factores como posibles condiciones que indicarían algún nivel de contribución en el proceso de descentralización sin cooptación. Por lo anterior, los resultados presentados a continuación son estrictamente exploratorios, elaborados de manera deductiva, no conduciendo a ninguna conclusión definitiva, reflexiones que como hemos dicho, deben ser profundizados y explicadas en futuras investigaciones.

\section{Las dimensiones de la cooptación}

La cooptación busca anular a la sociedad local en su petición de cuentas a la gestión, y a su vez, inhibe la demanda de mayor autonomía/descentralización, ya que requiere aliados nacionales para gestionar en la opacidad. Son cadenas de control social de favores menores a cambio de lealtad electoral, haciendo uso patrimonialista de los beneficios del Estado para sus grupos de apoyo en una red de "gestores territoriales" en el caso chileno (Durston, 2012).

En América Latina las grandes coaliciones y partidos, con matices dentro de un cultura presidencialista-centralista, logran una fuerte institucionalización de sus prácticas cooptado- 
ras que combinan la amenaza, los favores y la integración de los potenciales rivales a sus propias redes de reproducción del poder (Gandhi, 2008). La contratación de líderes vecinales en las planillas de empleados públicos, el subsidio a grupos de interés y partidarios, el financiamiento incluso de movimientos sociales afines, es parte de la sofisticada maquinaria de cooptación: "la capacidad de integrar actores estratégicos al poder dominante haciendo uso de mecanismos informales (prebendas, dinero) y formales en la integración al sistema de partidos" (Gerschewski, 2010:8).

En estos modelos importa fortalecer una Estado anómalo sin autonomía social, fusionando partido-instituciones en vez de consolidar la profesionalización, neutralidad de la administración y el rol de co-responsabilidad y control participativo de la sociedad civil. En los modelos cooptadores la burocracia es para controlar: "un conjunto de relaciones sociales de comando y obediencia que está jerárquicamente pautado por reglas formales y explícitas, vigentes en el seno de una organización compleja." (O’Donnell, 2008:3). La política se mueve por anular al otro (cooptación) en vez de empoderarlo (autonomía).

Wintrobe (1998) reconoce que el clientelismo busca tanto asegurar la cohesión de la población hacia el grupo dominante que gobierna, como el uso de repartir renta a líderes y dirigentes para evitar fracturas intra-élites. Al respecto para Selznick, cooptar es "el proceso de absorber nuevos elementos en la cúpula directiva o estructura dirigente de una organización como medio para evitar las amenazas a su estabilidad o existencia" (Selznick, 1993:208), aunque como sostiene Stefes (2006), este mecanismo no es sólo tiene como finalidad disciplinar y evitar rebeliones, también funciona para tener información y acceso a negocios ilícitos.

Los grupos presicráticos, que controlan la presidencia y el gobierno central (Valenzuela, 2007a), consideran que su tarea no es promover poder de otros y supervisar cumplimientos de normas y leyes con servicios sociales. Su rol fundamental es concentrar los recursos con discrecionalidad y disciplinar verticalmente a los entes subnacionales. La función movilizadora de recursos es monopólica: “distribuye y redistribuye los bienes y recursos materiales que controla según su voluntad, es decir, atribuye ingresos, extrae impuestos y destina servicios y riquezas" (Arbós y Giner, 1993:4). Mills (1967) señala la facultad que tendría esta de configurar una amalgama de vínculos asociativos que permita la organización necesaria para prever cambios en la mayoría gobernada, debido a la socialización y fidelización que existe entre sus elementos.

La cooptación y el clientelismo generan un Estado en las sombras donde los grupos de poder se reparten favores, desde comisiones ilegales, nepotismo, intercambio de cargos, asociaciones ilegales para comprar políticos opositores tal como la bullada oficina paralela de Montesinos, el asesor de Fujimori en Perú, o en una menor escala, en Chile con los bonos y recursos para grupos sociales alzados para evitar el conflicto. En el contexto de centralismo chileno, sin gobiernos regionales y municipales fuertes, destaca el tradicional ejemplo de los brokers: parlamentarios que tramitan y consiguen leyes especiales y recursos (Valenzuela, 1977). A su vez, se evidencia como en Argentina y México, el apoyo a agrupaciones sociales y ONGs afines, sin autonomía del Estado: "la contrapartida a la concesión estatal de subvenciones suele ser la neutralización del potencial contestatario de aquéllas, que acaban convir- 
tiéndose en ONGs especializadas en la gestión de las ayudas públicas que reciben" (Veredas, 2003:217). Esta es una función domesticadora ya que desmaximiza la fuerza contestataria de los grupos sociales. ${ }^{3}$

En el caso de Chile, Durston (2012:375) descubre los tres tipos de operadores en los programas públicos centralistas y clientelizados diseñados en el periodo gubernamental de la Concertación (1990-2009):

a) caudillo que asegura colocar a las personas en puestos públicos y consigue proyectos con comunidades.

b) brokers que es el intermediario político que consigue favores pero se relaciona más horizontalmente con las comunidades, a veces es parte de la misma y consigue recursos, aunque lleva un beneficio (trabajo, influencia).

c) gestor o gestionador es dirigente de juntas de vecinos u organizaciones comunitarias, que gana prestigio en el lobby en favor de proyectos.

En esta dimensión, la cooptación se asemeja al clientelismo tradicional (Schröter, 2010) en el uso de prebendas informales para lograr adhesión: "es ese sentimiento de permanencia el que nos demuestra que la institucionalización de los gobiernos que practican el clientelismo, se basan netamente en sus principios y sus prácticas, en cuanto a la movilización electoral que genere apoyo político, e informales, en cuanto se dan de manera complementaria a la política formal" (Auyero, 1997:36). Este fenómeno también se ha denominado política caciquil: "relaciones informales, no reguladas mediante contrato y distintas del orden institucional, por lo que han sido consideradas paralelas al mismo" (Moreno, 1995:194). Moreno añade que "ambos participantes (cliente y clientelista) no establecen un contacto puramente circunstancial, sino que lo mantienen durante cierto tiempo, renovándolo periódicamente y, aunque sea de manera débil, basándolo en la confianza mutua" (Moreno, 1995:197).

Sin embargo, este fenómeno para Moriconi tiene una contraparte, pues el orden dominante se sustenta en la complicidad-aceptación de la víctima, lo que puede darse a través de cuatro formas: victima -cómplice por miedo, interés, necesidad o ignorancia. En el plano del interés se encontraría el paternalismo, el clientelismo, caciquismo y la cooptación. "El dirigente ofrece y distribuye, no en beneficio de los demás, sino para legitimar su poder y mantener el apoyo masivo, pero sin impulsar cambios estructurales o axiomáticos" (Moriconi, 2009:130). Relación que implicaría que las bases estructurales de la sociedad deban mantenerse para que el paternalismo opere. "En definitiva, de manera recursiva la víctima-cómplice naturaliza su

\footnotetext{
${ }^{3}$ Como señala Zibechi (2010:50), "las organizaciones sociales, la economía solidaria, la autonomía y la horizontalidad, la educación popular, etc. han nacido en el conflicto social, pero separadas de ese conflicto se convierten en técnicas asépticas, esterilizadas de todo vínculo político-social, convirtiéndose en herramientas de la dominación, de la gobernabilidad".
} 
lugar social por un beneficio que siempre será mucho menor al beneficio otorgado al líder; beneficio menor que, a su vez, determina la inmovilidad social para que la situación se pueda mantener" (Moriconi, 2009:130).

De esta manera, es posible identificar diversos elementos que favorecen la cooptación, los que pueden ser agrupados en:

a) estructurales: favorecidas por el régimen político centralista, presidencialista, con débiles instituciones y alta discrecionalidad en el uso de recursos públicos, en el nombramiento de personal y en la asignación de contratos, sistemas electorales que favorecen grandes partidos/coaliciones hegemónicas y existencia de un alto peso de grupos económicos aliados al poder político o de las empresas públicas.

b) formales: la existencia de fondos discrecionales para negociar con grupos críticos, bonos de término de conflicto, posibilidad de leyes especiales, creación de comisiones de estudios, posibilidad de nombramientos de opositores en cargos de la administración y en la coalición o partido gobernante, amnistías.

c) informales: comisiones (coimas), contratos especiales, contratación de familiares, entrega de tierras, contratos o servicios.

d) sutiles: a los estudios clásicos de cooptación, agregamos los mecanismos sutiles - cuando los detentadores del poder nombran en comisiones, dan premios honoríficos y adulan a los actores rebeldes como manera de silenciarlos.

Con ello, los efectos de la cooptación se expresan a través de diversos mecanismos, y dimensiones, configurando condiciones para que las fronteras morales e institucionales de una sociedad se tornen difusas. Las estrategias e intereses de los grupos cooptadores, comienzan a ganar legitimidad social y política, generando que la demanda por mayor autonomía y descentralización se torne instrumental, y sin orientación a intereses colectivos, sino en función de intereses individuales y a veces criminales. En este sentido, creemos relevante la tarea de identificar posibles respuestas estructurales para una descentralización efectiva y autónoma, que restringa la capacidad cooptadora del poder central en las regiones.

La descentralización, no implica el fin de la cooptación, pero contribuye a la dispersión del poder, el que como señala Haldenwang (1990:67) “depende de la autonomía legal, financiera y organizativa de las instituciones descentralizadas y de su legitimación por medio de elecciones".

En el marco del proceso de descentralización que han experimentado los países latinoamericanos, casi todo ellos muestran avances significativos en lo que se refiere a la democratización de los procesos de elección de las autoridades locales e intermedias. Es así que tras el término de los regímenes autoritarios de los setenta y ochenta, se reinstaló la elección democrática de alcaldes o concejales e incluso otros, en el marco de procesos constituyentes, establecieron la elección democrática de autoridades regionales o departamentales como es el caso de Colombia y Perú. 


\section{Autonomía política y financiera}

Durante las décadas de los ochenta y noventa, la descentralización cobrará un nuevo impulso ${ }^{4}$ en el marco de procesos de reforma del Estado que, con matices, responderán a los lineamientos del Consenso de Washington y del paradigma neoliberal (Oszlak, 1997). En ese proceso, los gobiernos subnacionales, y especialmente los municipios, incrementarán sus recursos pero ligado a la transferencia de un conjunto de nuevas responsabilidades como la educación o la salud u otros componentes del gasto social en un proceso de "localización" de la cuestión social $^{5}$. Sin embargo, este proceso de descentralización de la política social estuvo acompañado de subvenciones insuficientes para cubrir los servicios con una calidad semejante al que antes proveía el Estado central. De esta forma, el predominio de lógica de agencia en el proceso de descentralización impulsado por las políticas de ajuste estructural hace que algunos prefieran referirse a este proceso como desconcentración por su énfasis administrativo (Coraggio, 1997).

Este panorama fundacional ha ido cambiando progresivamente y los gobiernos subnacionales han ido ganado en visibilidad ciudadana, autonomía económica, participación y transparencia. En el ámbito de las finanzas el porcentaje de gasto público municipal aumento hasta el 10\% a mediados de los ochenta para llegar a casi el 25\% (de la Cruz, Pineda y Pöschl, 2010). Sin embargo, siguen existiendo situaciones que afectan negativamente la autonomía de los gobiernos subnacionales y, con ello, sus capacidades para responder a las demandas de las ciudadanías locales y aportar al desarrollo de las comunidades locales.

Tabla 1

Finanzas intergubernamentales comparadas

\begin{tabular}{|lcccc|}
\hline & \multicolumn{2}{c}{ Promedio América Latina } & \multicolumn{2}{c|}{ Promedio países desarrollados } \\
\cline { 2 - 5 } & \multicolumn{2}{c}{ Ingresos } & \multicolumn{2}{c|}{ Ingresos } \\
\cline { 2 - 5 } & Porcentaje del PIB & Porcentaje total & Porcentaje del PIB & Porcentaje total \\
\hline Sector publico & 25,6 & 100 & 42,4 & 100 \\
Gobierno central & 20,9 & 81,6 & 27,8 & 65,5 \\
Estados & 3,4 & 13,3 & 9,0 & 21,2 \\
Municipios & 1,3 & 5,1 & 5,5 & 13,0 \\
\hline
\end{tabular}

\footnotetext{
${ }^{4}$ Anteriormente, si bien la tradición política Latinoamericana reconocía de larga data a las estructuras municipales, para mediados de la década del sesenta, la mayoría de los países latinoamericanos mostraba niveles de gasto municipal de alrededor del 3\% del gasto público total (Stöhr, 1972).

${ }^{5}$ A mediados de los ochenta, en el proceso de reestructuración de las políticas sociales (despojadas en su mayoría de pretensiones universalistas), se generó en Latinoamérica un proceso de privatización y descentralización (Ziccardi, 2001:103). Para Repetto, el resultado de este proceso fue "convertir a los municipios en actores de los programas destinados apaliar las problemáticas sociales, con lo cual se produce en muchos casos, una injusticia, porque son pocos los que cuentan con una infraestructura adecuada, en cuanto a personal capacitado y condiciones de administración modernas, y solo éstos están en condiciones de acceder a la administración de las políticas sociales, que les bajan desde la Nación, Provincia u organismos internacionales" (Repetto, 2000:4).
} 


\begin{tabular}{|c|c|c|c|c|}
\hline \multirow[b]{2}{*}{ Gobierno central } & \multicolumn{2}{|c|}{ Después de transferencias } & \multicolumn{2}{|c|}{ Después de transferencias } \\
\hline & 16,1 & 64,9 & 22,8 & 53,5 \\
\hline Estados & 6,1 & 24,6 & 11,7 & 27,5 \\
\hline \multirow[t]{3}{*}{ Municipios } & 2,6 & 10,5 & 8,1 & 19 \\
\hline & \multicolumn{2}{|c|}{ Gastos } & \multicolumn{2}{|c|}{ Gastos } \\
\hline & Porcentaje del PIB & Porcentaje total & Porcentaje del PIB & Porcentaje total \\
\hline Sector publico & 27,9 & 100 & 47,8 & 100 \\
\hline Gobierno central & 18,4 & 65,9 & 27,2 & 56,9 \\
\hline Estados & 6,9 & 24,7 & 12,6 & 26,4 \\
\hline Municipios & 2,6 & 9,3 & 8,0 & 16,7 \\
\hline
\end{tabular}

Fuente: De la Cruz, Pineda y Pöschl (2010:50).

El incremento de los recursos subnacionales, coexiste en América Latina, con una elevada concentración espacial de la población y de la actividad económica. Dos diferencias son posibles de observar en contraste con los países de la OCDE: estos poseen una menor concentración y una menor disparidad en el PIB per cápita territorial; en definitiva, "la concentración espacial de la actividad económica y de la población no necesariamente implica brechas significativas de riqueza entre territorios. Pero en América Latina la concentración y las disparidades han ido de la mano y han provocado una situación de inequidad territorial" (Cepal, 2014:163). ${ }^{6}$

Desde este punto de vista, la literatura promueve diversas razones que justifican la necesidad de grados de autonomía fiscal, como condición necesaria para una descentralización exitosa, atribuyendo algunas causas como:

a) promoción de la eficiencia económica al responsabilizar del financiamiento de los bienes públicos a las comunidades que manifiestan sus preferencias;

b) fortalecimiento de la identificación entre ciudadanía y gobierno local;

c) aumento de posibilidades en la ciudadanía local para presionar y exigir cuentas a las autoridades locales;

d) ajustar más fácilmente la carga tributaria de actividades que se modifican rápidamente (Cabrero, 2006).

Desde la perspectiva fiscal, los procesos de descentralización pueden analizarse desde dos enfoques principales: el de la elección pública y el de agente principal. Desde el punto de

\footnotetext{
${ }^{6}$ En este mismo estudio es interesante destacar que la mayoría de los países europeos de la OCDE muestran disminución en la brecha del PIB per cápita de la región más rica y más pobre. En América Latina solo dos países (Chile y Perú) muestran disminuciones.
} 
vista del primero "se asimila la eficiencia distributiva con la capacitada de asignar funciones y competencias entre niveles de gobierno de tal manera que la asignación de recursos responda a las preferencias de las comunidades que apropian sus beneficios" (Marcel, 2008:7). Desde el segundo enfoque, se privilegia la definición central de las políticas públicas y el aprovechamiento de las economías de escala en el cumplimiento de las definiciones nacionales contribuyendo de esa manera, a la eficiencia en la asignación de recursos públicos.

Como no hay modelos puros, los resultados del proceso de descentralización "depende de que la funciones que responden al enfoque de elección pública se desempeñen y se financien en condiciones que faciliten el ejercicio de la autonomía local" (Marcel, 2008:4) y que se cuente con incentivos y supervisión adecuados para aquellas funciones en que los gobiernos locales sean agentes del gobierno central.

Si las atribuciones fiscales de los gobiernos locales no se alinean con el ejercicio de la autonomía política, se genera una brecha entre las responsabilidades asignadas y la capacidad gubernamental de financiarlas con cargo a recursos propios que se denomina desequilibrio vertical. Este desequilibrio se complementa con otro que está a la base de quienes observan con preocupación un proceso de esta naturaleza y que justifica la existencia de transferencias interterritoriales: los desequilibrios horizontales entre territorios que tienen diferencias importantes en dimensiones como la demográfica, su grado de urbanización, su perfil productivo y muy especialmente, en su capacidad para generar recursos.

La siguiente tabla muestra los grados de descentralización de recursos en Latinoamérica.

Quadro 1

Recursos descentralizados del total de gasto público

\begin{tabular}{|ll|}
\hline Nivel & Países \\
\hline Alto: más de $20 \%$ & Brasil, Argentina, Perú, Colombia, México, Ecuador y Bolivia \\
Medio: Entre $10 \%$ y $20 \%$ & Chile, Uruguay y Venezuela \\
Bajo: Menos de $10 \%$ & $\begin{array}{l}\text { R. Dominicana, Paraguay, El Salvador, Guatemala, Nicaragua, Honduras, Jamaica, } \\
\text { Panamá, Costa Rica, Cuba }\end{array}$ \\
\hline
\end{tabular}

Fuente: Rosales (2012).

Si bien los recursos que recaudan los gobiernos locales varían de un país a otro, en la mayoría de ellos es posible identificar un conjunto de ingresos semejantes tales como las transferencias (generales o específicas; condicionadas o no condicionadas; compensatorias), endeudamiento, tasas por servicios o venta de servicios; impuestos locales o impuestos nacionales compartidos. En algunos casos, los impuestos que son de beneficio de los gobiernos locales son recaudados en un nivel superior y luego transferidos a éste. En otros casos, los entes locales se benefician de recursos generados a partir de los gravámenes que se aplican a las actividades extractivas como la de hidrocarburos o la minería a través de las regalías o de la distribución de porcentajes de la recaudación tributaria nacional. 
La evaluación de la autonomía local depende, entre otros factores, de la autonomía financiera. Y la autonomía financiera está relacionada con la existencia de transferencias no condicionadas (es decir, aquellas sobre las cuales los gobiernos locales pueden disponer sin restricciones del gobierno central) más la capacidad de generar recursos propios, la cual a su vez se observa en la capacidad de definir autónomamente tanto la base como la cuota tributaria.

Como resultado de estos dos criterios, se obtiene la siguiente clasificación: el gobierno local controla tanto la tasa como la base impositiva, el gobierno local fija la cuota tributaria, el gobierno local fija la tasa impositiva, acuerdos de distribución de ingresos impositivos, el gobierno local determina el reparto de ingresos. El primero representa el grado máximo de autonomía; "como los impuestos locales normalmente representan la principal fuente de ingresos autónoma para los gobiernos locales, la capacidad de influir en la base impositiva, la cuota tributaria o los ingresos recaudados es una condición importante. Si dispone de esa capacidad, un gobierno local puede adaptar el nivel de servicios a sus circunstancias financieras" (FAO, 2004:18).

En América Latina, las capacidades de los gobiernos subnacionales se ven mermadas dada la escasa autonomía tanto para definir nuevos tributos como para definir la base y la tasa de aquellos impuestos que son de su responsabilidad: "los gobiernos municipales por lo general tienen el control sobre los impuestos a la propiedad, pero en muchos casos el gobierno nacional tiene el poder de definir la base y la tasa de ese impuesto, lo que ocasiona frecuentemente retrasos en los valores catastrales y baja recaudación. El resultado de esta situación es que los gobiernos subnacionales exhiben habitualmente una fuerte dependencia de las transferencias de los gobiernos nacionales, lo cual alcanza en promedio más del 50\% en las economías grandes y medianas de la región y, en casos extremos, el 90\% de los ingresos de los estados y municipios. Solo aquellos municipios de las grandes metrópolis y de algunas ciudades intermedias que tienen muy buena gestión fiscal logran recaudar ingresos propios superiores al 70\% de sus ingresos totales" (De la Cruz, Pineda y Pöschl, 2010:48).

Por otro lado, la ausencia de atribuciones en materia fiscal que permita a los gobiernos locales mejorar su capacidad para recaudar recursos propios afecta negativamente tanto su autonomía respecto de los poderes centrales como sus posibilidades de responder a las "preferencias" de la ciudadanía local en un contexto de mayor participación y control ciudadanos.

Esta evidencia se refuerza al observar los resultados de un estudio realizado por la consultora PriceWaterhouse Coopers (citado por de la Cruz, Pineda y Pöschl, 2010) que relaciona positivamente el grado de descentralización con el nivel de desarrollo local en siete grandes ciudades latinoamericanas. El conjunto de estas ciudades generan una proporción mayor de producción económica que la proporción de su población en relación al total nacional; en promedio, con el 25,7\% de la población total aportan el 33,4\% de la PIB. Al cruzar este dato con los niveles de descentralización de dichas urbes, se puede observar "una correlación positiva entre el grado de descentralización y la contribución de las ciudades a la actividad económica per cápita del país" (De la Cruz, Pineda y Pöschl, 2010:56) destacándose el caso de la ciudad de Santiago, que en el marco de un país con indicadores exitosos en materia de crecimiento económico, muestra una baja productividad per cápita que podría explicarse por su débil autonomía. 
En la misma línea, otros estudios identifican una relación virtuosa entre, por un lado, el dinamismo de las grandes ciudades y el crecimiento de la economía en su conjunto y, por el otro, entre ese dinamismo y el comportamiento positivo en cuatro conjunto de indicadores, entre ellos, las finanzas y la gestión de gobierno. A su vez, en este último indicador se consideran la disponibilidad de recursos, la capacidad para generar recursos propios y la inversión y la participación y transparencia. De esta manera, como muestra un balance de la autonomía (descentralización) tanto política como fiscal en el Continente (Gargarella y Arballo, 2012), se puede observar la relación causal entre los países de mayor descentralización con las mejores gestiones territoriales del Continente:

\section{Tabla 2 \\ Países con mayor federalismo político-fiscal y buenas gestiones municipales-regionales 2010}

\begin{tabular}{|c|c|c|c|}
\hline País & $\begin{array}{c}\text { Índice } \\
\text { Descentralización política }\end{array}$ & $\begin{array}{l}\text { Índice } \\
\text { Autonomía fiscal }\end{array}$ & $\begin{array}{c}\text { Municipios } \\
\text { Regiones emprendedoras }\end{array}$ \\
\hline Brasil & 100 & 92 & $\begin{array}{l}\text { Porto Alegre: presupuesto participativo } \\
\text { Curitiba: primer metro bus y medio ambiente }\end{array}$ \\
\hline Argentina & 92 & 83 & $\begin{array}{l}\text { Rosario: salud y educación } \\
\text { Mendoza y San Luis: fomento económico local }\end{array}$ \\
\hline Colombia & 58 & 75 & Bogotá: predial, ciudadanía activa, combate criminalidad \\
\hline Ecuador & 67 & 75 & $\begin{array}{l}\text { Quito: patrimonio } \\
\text { Guayaquil: cooperación público-privada }\end{array}$ \\
\hline México & 92 & 50 & $\begin{array}{l}\text { Guadalajara: competitividad } \\
\text { Chiapas: poder indígena, cohesión }\end{array}$ \\
\hline Uruguay & 58 & 50 & Montevideo: seguridad, participación \\
\hline Bolivia & 67 & 50 & $\begin{array}{l}\text { El Alto: poder popular/servicios } \\
\text { Santa Cruz: renovación urbana }\end{array}$ \\
\hline
\end{tabular}

Fuentes: Índices de Descentralización Política y Fiscal traducidos y fusionados de Gargarella y Arballo (2012:27-28). Casos de emprendimientos subnacionales confeccionados por el autor en base a estudio para GTZ Colombia "Veinte rasgos de los gobiernos territoriales emprendedores en América Latina: conceptos y casos" (Valenzuela, 2007a:13-24).

El resto de los países se ubican en promedio bajo un 50\% en el índice elaborado por Gargarella y Arballo y Cepal-GIZ a 12 países. De esto se pueden destacar dos reflexiones:

a) Es difícil que nazca una gestión municipal emblemática en países centralizados, como el caso chileno, ${ }^{7}$ donde incluso Santiago carece de gobierno metropolitano, por lo que los

\footnotetext{
${ }^{7}$ El caso de Chile ha caminado en el sentido contrario, debido a que el estado central ha aumentado la exención del impuesto predial de contribuciones de bienes raíces, al 70\% de los predios del país con la pasividad de los mu-
} 
ministerios implementan las principales políticas, desde los parques urbanos al sistema de transporte.

b) La autonomía política y financiera no es condición suficiente de buena gestión subnacional, pero es condición necesaria. De hecho, en estos países existen también muy malas experiencias de gobiernos territoriales, capturados por las mafias (México), violentos (Colombia, Brazil) o endeudados/corruptos (Argentina, Ecuador). Se requiere de manera sinergética, como se ha dicho, de una adecuada institucionalización y sociedad civil fuerte que controla el poder (incluyendo la existencia de oposición).

El punto es que los países centralistas-ordenados como Chile, logran nivelar y generar mínimos, pero no permiten la innovación relevante desde lo territorial y subnacional. Los países descentralizados aunque vivan crisis, tienen polos de desarrollo autónomo que les permiten generar políticas y construcción de gobernanza desde lo local.

\section{Participación ciudadana y control democrático}

La centralización del poder reduce, casi hasta desaparecer, la fuerza de las entidades territoriales, genera círculos de exclusión política y despierta sentimientos de indiferencia y apatía en la ciudadanía, porque el monopolio del poder aleja cada vez más a las autoridades de la sociedad y no produce la legitimidad que proporciona la participación ciudadana. (Barrera, 2009:2)

Siguiendo la línea anterior, al interior de los distintos enfoques descentralizadores (económico, sociológico, nueva gestión pública, politológico y de optimismo multilateral), se encuentra con diferentes énfasis la noción de la descentralización como un proceso inclusivo de la ciudadanía en las decisiones públicas, que permite fortalecer la democracia (Montecinos, 2006:3). Así, mientras algunos enfatizan en las bondades de un Estado más cercano para focalizar el gasto público, otros sustentados en un ideal toquevillano ${ }^{8}$ enfatizan en lo local como el espacio natural para ejercer la política y la actividad colectiva; o bien como una condición necesaria para una democracia radical.

Sin embargo, diversos autores sostienen que la relación entre descentralización- participación y democratización no es del todo clara bajo ciertas circunstancias. Uno de estos aspectos es la debilidad de las instituciones que posibilita la captura de los recursos transferidos

nicipios, los que se han acostumbrado en su mayoría a vivir de las transferencias del Fondo Común Municipal y de los fondos concursables del Estado, lo que obliga a una domesticación e inclusión en redes cooptativas. Mientras en el mundo se recauda el 1,04\% del PIB en impuesto predial, en América Latina es sólo el 0,37\% versus el 2,12 de la OECD. Chile retrocedió del 0,70 en el 2000 al 0,59 el 2007 (Sepúlveda y Martínez-Vásquez, 2012:175-176). ${ }^{8}$ Alexis de Tocqueville en La democracia en América sostenía que "la comuna es la única asociación que se encuentra de tal modo en la naturaleza, que por doquiera que hay hombres reunidos, se forma por sí misma una comuna" (Tocqueville, 2011:77-78). 
por elites subnacionales y caciques locales (Montecinos, 2006:11). Otro elemento se relaciona con que la descentralización no necesariamente incrementa la eficiencia pública, ni revierte la democratización en Latinoamérica debido a la existencia de una cultura política asistencialista y cooptativa. Así para Mascareño (2008:13), el riesgo caudillista y personalista contradice el principio madisoniano de una mejor accountability local debido a que no siempre existe separación entre poderes, medios de comunicación libres, audiencias públicas y ciudadanas.

En esta línea, algunos casos interesantes en el contexto de una cultura política poco favorable o ante la corrupción en Estado fallidos y amenazados por poderes paralelos que capturan incluso las propias instancias de control, se contrasta facilitando y fortaleciendo la acción del control social de los ciudadanos en todos los niveles de la gestión, no sólo la inversión (Valenzuela, 2005). Las mejores prácticas en América Latina demuestran que el rol de control es tripartito: Estado, sector privado y sociedad civil (Fontra, 2012), lo que va en la línea mundial de fortalecer el rol activo de la sociedad civil para enfrentar la grave corrupción, lo que junto a la criminalidad son agendas hegemónicas en el mundo de hoy, sobre todo en África, América Latina y el sudeste asiático (Landell-Mills, 2013).

La existencia de poderes paralelos al Estado, mafias y redes económicas, generan la penetración y cooptación de niveles estatales y un clima generalizado de extorsión, amenazas e impunidad. En este cuadro, no es posible asegurar el funcionamiento normal de los municipios, muchos de los cuales, por ejemplo, para lograr adjudicarse proyectos desde agencias nacionales y fondos departamentales (regiones), deben aceptar malas prácticas y hacer un extensivo uso de consultoras ligadas a poderes parlamentarios y políticos. Entre estas malas prácticas se encuentra la llamada obra gris, para cuya obtención se privilegian los contratos de mejoras de caminos e infraestructura, dejando de lado la inversión en servicios públicos esenciales como el agua ya que estos último permiten menos posibilidades para el robo y la corrupción.

Gutafsson (2008), en su estudio de las comunidades indígenas en los Andes peruanos, nos entrega una serie de elementos comparativos respecto a la desmovilización de comunidades. Parte de la premisa de que las diferencias sistemáticas entre la participación política de las diversas categorías sociales y las profundas desigualdades socioeconómicas generando una desigual distribución del poder político. En tal desigualdad en el acceso al poder, es donde se suceden los escenarios de clientelismo y cooptación, que buscar acarrear demandas efectivas, acallando a las comunidades, ya sea con la entrega de beneficios de manera personalista a ciertos líderes de las comunidades, pervirtiendo el desarrollo de un programa participativo que pudieran empoderar estratégicamente el poder local.

En esta línea, una política descentralizadora debe asumir aspectos como la fragmentación de la sociedad civil y el tejido social (Delamaza et al., 2012), lo que a la larga es una condición necesaria para el control ciudadano. A su vez, es necesario responder a interrogantes sobre cómo se determina quienes y cuando participan, lo que a juicio de Mascareño, no siempre queda del todo claro, generando una tendencia en Latinoamérica a favorecer las organizaciones "oficiales", con "membresía" y asociados a los centros del poder, es decir una élite dirigencial (Penaglia, 2011). 
Por otro lado, es necesario considerar la relación entre sociedad civil y poder institucional. Como señala Mascareño (2008), en muchas ocasiones las autoridades locales cierran los canales de participación considerándolos riesgosos, negándose a la distribución del poder. Esto redunda en que gran parte de los mecanismos de participación son principalmente retóricos, no vinculantes o en su defecto implementados sobre aspectos marginales (política y presupuestariamente) de las grandes decisiones.

Sin participación empoderada, institucionalizada y con capacidad de controlar las gestiones (rendición de cuentas), la descentralización queda a merced de mafias o caudillismos locales. Países que han avanzado en desarrollo, exhiben mayor apertura a modelos de presupuestos participativos, sobre todo en el sur (Uruguay, Brasil, Argentina, y en menor medida Chile). La participación local en Chile es pobre, retórica, con baja implementación de mecanismos de democracia directa. Según el Latinobarómetro es el penúltimo país en asistencia anual de ciudadanos a reuniones con el municipio, ya que todo se alcaldiza y concentra en pequeños concejos, lo que muestra una debilidad de la esfera pública, debates y deliberación (Valenzuela, 2013). El caso de Bogotá para Todos es notable, ya que no sólo mide las diversas dimensiones de la calidad de vida (salud, educación, empleo), los servicios municipales (aseo, parques, ruido, transporte, basura), sino también hace una auditoría externa las finanzas locales y la administración. El siguiente extracto de su informe 2012 es ilustrativo, donde valora y critica con datos precisos:

En 2012, el Presupuesto General Distrital llegó a los \$12,9 billones, un monto que mantiene estabilidad frente a 2011. Bogotá es una ciudad que ha mejorado su capacidad de autofinanciación, lo que mantiene la tendencia a que dependa cada vez menos de las transferencias del Sistema General de Participaciones SGP, que representan 22\% del total del presupuesto de la Administración Central (...) En ese mismo sentido, vale la pena destacar que el 90\% de los contribuyentes de Bogotá paga sus impuestos (ICA, predial y vehículos) y que el 70\% de los contribuyentes de predial y 52\% de vehículos (...) Los gastos de inversión mantienen una alta participación en el presupuesto, en 2012, fueron el 81\% de los gastos de la Administración Central y el 79\% de los gastos de los establecimientos públicos. El servicio de deuda y los gastos de funcionamiento del Distrito se mantienen por debajo del 20\%(...)Es preocupante que la ejecución del Presupuesto Anual de Inversión Directa por parte de las entidades apenas llegó al $85,7 \%$ de recursos comprometidos, lo que quiere decir que no se ejecutaron alrededor de \$1 billón. (Bogotá como vamos, 2012:88)

Gran parte de los claro oscuros entorno a la relación participación, democracia y descentralización pasa en primer lugar, por la creación de mecanismos que permitan el fortalecimiento efectivo de la sociedad civil autónoma, propiciando la distribución del poder, favoreciendo la asociatividad y mejorando los mecanismos de control ciudadano e información (lo que involucra temas como la concentración de los medios de comunicación, necesarios para la construcción del espacio público local y regional).

A ello debe agregarse que la participación sea efectivamente incluida en la gestión pública a través de estándares que permitan diferenciar la retórica participativa que involucra 
únicamente aspectos procedimentales de checklist convocando a organizaciones afines vs la participación empoderada que permite una involucramiento directo en los distintos tramos de la escala de participación (Hart, 1993).

Por ello para se cumpliera el ideal democratizador de la sociedad civil a través de la participación, es "necesario generar una nueva cultura política capaz de evitar que las organizaciones se convirtiesen en grupos auxiliares de la acción del estado o en organizaciones funcionales de los partidos y, por el contrario, pudieran profundizar su carácter transformador de la relación estado-sociedad" (Mascareño, 2008:10).

\section{Institucionalización}

Como lo hemos planteado anteriormente, el proceso descentralizador aparece como la mejor estrategia para la profundización de la democracia, generación de mayor gobernabilidad y equidad, mediante la trasferencia por parte del nivel central de competencias, responsabilidades y recursos a las unidades territoriales (Rave, 2003). Sin embargo, un proceso de descentralización cooptado, inserto en un marco de prácticas corruptas, pondría en peligro el logro de los deseables objetivos de la descentralización.

Es así como el enfoque neo institucionalista, podría explicar en parte el surgimiento de una descentralización cooptada sujeta a prácticas deshonestas por parte de funcionarios subnacionales, además de entregarnos luces sobre cómo prevenir aquellos comportamientos en organizaciones locales. Esta perspectiva asumiría que los servidores públicos cuentan con un rol preponderante en el logro de los objetivos de la descentralización sin cooptación, promoviendo o limitando los objetivos de mayor desarrollo social y económico en los territorios. El anterior supuesto considera así mismo, la capacidad con las que contarían las instituciones, en cuanto a moldear y articular la conducta de los seres humanos (Berger, 2003).

De esta forma, las instituciones son reconocidas como factor determinante en el desarrollo de las naciones por la literatura especializada. A nivel macro, las estructuras legales como gubernamentales, son vistas como elementos claves en el desempeño económico, político y social de los países. Por otra parte y a nivel micro, las instituciones influirían en el comportamiento de los individuos, organizando sus interacciones en la dinámica social. En este sentido, tanto normas informales (tradiciones, códigos de conducta, valores etc.), como formales (organizaciones, políticas, leyes, decretos, etc.), contribuirían a disminuir la incertidumbre en la interacción humana, modificando la conducta de los individuos (North, 1993).

En términos específicos, las instituciones según los precursores esta línea de investigación (North, 1993; March y Olsen, 1984; DiMaggio y Powell, 1983) reducirían los costos de transacción de las relaciones sociales, políticas y económicas de los agentes. Entendemos por costos de transacción en este caso, costos relacionados con hacer cumplir normas y contratos establecidos por dichos agentes sociales. Según North (1993), los costos de transacción en modelos jerárquicos como las organizaciones gubernamentales, se refieren específicamente a los costos (esfuerzos) para limitar o restringir la acción del individuo en la organización. 
Bajo esta perspectiva, las prácticas corruptas de una organización subnacional, se explicarían a partir de la inexistencia de instituciones o de bajos niveles de efectividad de las mismas en la disminución de la incertidumbre, no limitando dichas estructuras, la acción individual de los funcionarios públicos para la realización de prácticas deshonestas. Este enfoque supone sin embargo, que el funcionario público es un ser racional (Coase, 1937), capaz de calcular el costo y beneficio de actos corruptos, así como de determinar la probabilidad de ser eventualmente descubierto y sancionado (March y Olsen, 1976). Las instituciones efectivas de esta manera, serían aquellas que limitan las acciones indeseadas de los funcionarios de las organizaciones locales, aumentando los costos de cometer una acción deshonesta y reduciendo los beneficios potenciales que dichos funcionarios pudiesen obtener producto de estas conductas, fortaleciendo entonces los incentivos para un comportamiento honesto (Coase, 1937).

De esta manera, el neo institucionalismo sugiere que la descentralización cooptada o corrupta, estaría influida por el tipo de instituciones definidas a nivel subnacional, las que podrían incentivar o limitar las prácticas corruptas. Una descentralización sin cooptación entonces, tendría como condición necesaria una estructura institucional que disminuya el nivel de incertidumbre en las transacciones políticas y sociales, así como reduciendo los costos de transacción entre los agentes locales, limitando el margen de acción de las autoridades y funcionarios corruptos, aumentando por otra parte, el costo de comportamientos deshonestos, así como disminuyendo el potencial beneficio derivado de dichas prácticas.

Asimismo, el asunto de la institucionalidad no es sólo de la burocracia de municipios y gobiernos regionales/provinciales, también de convertir las innovaciones, la planificación, las políticas y programas en modelos con reglamentos, recursos y recurrencia que genere institucionalización de ciertos principios (Valenzuela, 1996). En este sentido, el caso holandés, ${ }^{9}$ específicamente su práctica de gestión de riesgos, aparece como un modelo innovador de estructura institucional y gestión local que vale la pena observar (Cienfuegos, 2011).

Desde una perspectiva de instituciones informales, en cuanto a coordinar e influir en el comportamiento de los seres humanos, el experto del Banco Mundial Tim Campbell (1999),

\footnotetext{
${ }^{9}$ Holanda puede ser definido como un estado unitario descentralizado, donde los municipios son definidos como instituciones públicas autónomas y co-gubernamentales (Van Helden y Ter Bogt, 2001). Esta mayor autonomía sin embargo, ha estado acompañada por una profesionalización de la gestión gubernamental local y el diseño de innovadores "instituciones" o reglas que disminuyan los costos de transacción y la incertidumbre a la hora de controlar y monitorear el desempeño de las entidades gubernamentales locales. Es así como desde mediados de la década de los 80 podemos observar en los gobiernos locales de los países bajos, la incorporación de las mejores prácticas de gestión, enfocadas a la rendición de cuentas en función de resultados (Hood, 1995). Otro ordenamiento institucional innovador del caso de Holandés que contribuiría a un mantener un diseño descentralizado no cooptado, limitando el comportamiento de los funcionarios públicos, es el modelo de gestión de riesgos que tanto las provincias como municipios deben implementar (Cienfuegos, 2011). Es así como estas entidades deben determinar el alcance de riesgos potenciales que enfrenta su organización, incluyendo una suerte de "provisión" o reserva en su presupuesto, de manera de mitigar su efecto en el caso de materializarse. Esta política de riesgos, denominada también como "resiliencia financiera" de los gobiernos locales, permite prevenir posibles déficit presupuestarios que pongan en peligro la continuidad de la operación de la entidad y la provisión de servicios críticos para la comunidad.
} 
resalta la situación de Rancagua en Chile, a partir de los modelos participativos ahí encontrados. Es así como este caso ilustraría la existencia de estructuras y prácticas informales que habrían limitado el actuar deshonesto, contribuyendo a la participación y transparencia de la gestión municipal a través de la coordinación y participación en la toma de decisiones de actores públicos y privados. Es así como desde las administraciones concertacionistas en los 1990s a las del alcalde de la UDI reelecto el año 2012, se gestó en Rancagua un modelo caracterizado por la proximidad con las organizaciones sociales en temas presupuestarios, Fondo de Desarrollo Vecinal, información y trasparencia, cofinanciamiento de obras, mesas de priorización barrial, planificación participativa con los actores, cooperación público-privada, entre otras (Valenzuela, 1996). Es decir, más allá de los cambios institucionales formales, se fortaleció un modus operandis (instituciones informales) que perdura, el que tiene legitimidad en la población y en los funcionarios municipales. Lo anterior permitió así mismo, despersonalizar el poder de la autoridad alcaldía, sobreponiendo a las dificultades de recursos y competencias escasas a nivel municipal (Valenzuela, 1998).

El enfoque en cuanto a impulsar políticas y acciones municipales a través de acuerdos con una red diversa de entes públicos y privados, es catalogado como una perspectiva "interactiva" de gobernanza y toma de decisiones por la literatura especializada, donde la acción colectiva toma un rol preponderante en el diseño y ejecución de políticas públicas por parte de gobiernos subnacionales. De esta forma el foco no está dado en el logro de objetivos locales por actores específicos, sino en la forma como los distintos actores ajustan sus estrategias en función de acciones y resultados colectivos (Kickert, 1997). En este sentido, los conceptos relevantes son: actores, estrategias y coaliciones, donde la "institución" informal de red, implica dependencia mutua de los actores en razón de la división de recursos e interdependencia de sus objetivos.

Sin embargo reportado por Edelenebos (2005), no siempre podemos asumir que la introducción de prácticas "interactivas" de gobernanza estará acompañada de la reevaluación o rediseño de instituciones formales existentes. Es así como tanto el proceso de coordinación interinstitucional, como el proceso de involucramiento ciudadano en la toma de decisiones, establecería un nuevo orden informal que conflictúa con las instituciones formales existentes, generando una tensión que da cuenta de una suerte de "falta de nexo institucional" entre el proceso interactivo y participativo a nivel municipal y el ámbito formal de las decisiones locales, lo que finalmente redunda en un proceso interactivo falto de sentido e incapacitado de poder formal en la toma de decisiones (Edelenebos, 2005).

Finalmente entonces, si bien las instituciones pudiesen evitar el surgimiento de una descentralización cooptada sujeta a prácticas deshonestas por los tomadores de decisiones, estableciendo reglas y comportamientos que disminuyan costos de transacción y favorezcan el control y la transparencia; tanto instituciones formales como informales, deben estar dotadas de capacidad técnica, como de instrumentos legales que les permitan absorber el amplio rango de ideas, planes y demandas de surgen en el territorio, estableciéndose como un pilar robusto y sostenible en el andamiaje descentralizador no cooptativo. 


\section{Conclusión}

El modelo cooptador es parte de la cultura presidencialista latinoamericana pero se exacerba en países donde se designa a las autoridades regionales y los parlamentarios no tienen contrapesos de poder territorial. Para la maquinaria cooptadora lo esencial es no aceptar el poder del otro, lo que elimina la premisa democrática del conflicto, la autonomía y la diversidad. La cooptación construye un orden en base a la manipulación, la repartición formal de rentas menores y la distribución informal, pero masiva, de rentas mayores a la red corrupta paralela al estado formal.

Sin embargo, como argumento contra hegemónico frente a la idea de fatalidad centralista y cooptadora en América latina, en el presente artículo se presentan dimensiones para un modelo democrático-descentralizado con menos discrecionalidad y fuerte autonomía a los entes subnacionales, en un ejercicio básico de oponer a la cooptación un horizonte liberador.

En este plano se proponen tres pilares para una descentralización efectiva sin cooptación y clientelismo:

a) Autonomía política y financiera: La mayoría de los estados Latinoamericanos posen modelos constitucionales centro-federalistas, con poca autonomía legislativa y de gestión de entes subnacionales, además de base fiscal débil dependiente de trasferencias centrales. Mientras los países desarrollados de la OECD transfieren sólo el 10\% del PIB en tributos a municipios y regiones (las que cuentan con su propia base fiscal y recolectan los impuestos), en América Latina llega al 21\% en promedio, lo que evidencia un modelo verticalista (Brosio y Jiménez, 2012:3).

b) Instituciones reales, capaces de generar gobernabilidad: La descentralización es la generación de instituciones reales capaces de generar gobernabilidad, compatibilizando dos visiones. Aquella que la liga a la burocracia (weberiana) y la más moderna que connota las redes de gobernanza plurales donde los entes subnacionales crecen en influencia cuando pactan con otros actores públicos, privados y sociales (Valenzuela, 1998). Las redes de gobernanza cooperativas y virtuosas son nuevas formas de crear instituciones (entendidas como recurrencias en generar valores públicos), en oposición a redes cooptativas que capturan recursos públicos para bienes privados o sectarios. Esta adaptabilidad es la que se encuentra vulnerable a prácticas cooptativas por parte de la elite política, donde sólo prevalece el culto al orden y el poder personalista, ya "que la necesidad básica de todos los sistemas empíricos es mantener la integridad y continuidad del sistema en si” (Selznick, 1993:201).

c) Finalmente, no es posible construir un proceso descentralizador sin democratización, participación ciudadana y empoderamiento, lo que permitiría transformar el curso de las agendas políticas y controlar el uso del poder para liberarlo de la cooptación autoritaria y privatista. Los países con mayor subdesarrollo combinan el poco poder subnacional con la corrupción y modelos retóricos y clientelares de participación (se moviliza a los grupos para dar pequeños subsidios monetarios o en alimentos). En esta línea, un fortalecimiento del capital social y los modelos sustantivos de participación, son mecanismos que limitan las 
zonas grises de la acción pública, favoreciendo el control, monitoreo del gasto y resultados del gobierno (Landell-Mills, 2013).

\section{Referencias}

ARBÓS, Xavier; GINER, Salvador. La gobernabilidad: ciudadanía y democracia en la encrucijada mundial. Madri: Siglo XXI, 1993.

AUYERO, Javier. Evita como "performance". Mediación y resolución de problemas entre los pobres urbanos del Gran Buenos Aires. En: AUYERO, Javier (Comp.). ¿Favores por votos? Estudios sobre clientelismo político contemporáneo. Buenos Aires: Losada, 1997. p. 32-52.

BALLART, Xavier; RAMIÓ, Carles (Ed.). Lecturas de teoría de la organización. Madri: Ministerio para las Administraciones Públicas, 1993.

BARRERA, Sandra. La descentralización crea espacios para la participación ciudadana y comunitaria en la vida pública. Bogotá: Universidad Colegio Mayor de Nuestra Señora del Rosario, 2009.

BERGER, Peter. La construcción social de la realidad. Buenos Aires: Amorrortu, 2003.

BLALOCK, Hubert. Conceptualization and measurement in the social sciences. Londres: Sage, 1982.

BOGOTÁ COMO VAMOS. Informe de indicadores de calidad de vida de Bogotá. Bogotá: Fundación Corona-U. Javierana, El Tiempo, Cámara de Comercio, 2012.

BROSIO, Giorgio; JIMÉNEZ, Juan Pablo. Decentralization and reform in Latin America, improving intergovernmental relations. Londres: Cepal (Ecla)-GIZ, 2012.

CABRERO, Enrique. Los retos institucionales de la descentralización fiscal en América Latina. México: Cide, 2006.

CADENA, Andres et al. Construyendo ciudades competitivas: la clave para el crecimiento de América Latina. Seúl: McKinsey Global Institute, 2011.

CAMPBELL, Tim. La descentralización, las políticas sociales y el municipio: los casos de Chile y Bolivia. Bogotá: Riadel, 1999.

CEPAL. La hora de la igualdad. Santiago: Cepal, 2014.

CEPAL. Rentas de recursos naturales no renovables en A. Latina y el caribe: evolución y participación estatal, 1990-2010. Santiago: Cepal-GIZ, 2013.

CIENFUEGOS, Ignacio. Risk management policy in dutch municipalities: understanding the process, identifying its strengths and visualizing the possible improvements. Revista Enfoques, Ciencia Política y Administración Pública, Universidad Central, v. 9, n. 14, p. 155-176, 2011.

COASE, Ronald. The nature of the firm. Economica, v. 4, n. 16, p. 386-405, 1937.

CORAGGIO, José Luis. Descentralización, el día después. Buenos Aires: UBA, 1997. 
CUNILL GRAU, Nuria. ¿Mercantilización y neo-clientelismo o reconstrucción de la administración pública? Retos de las reformas de segunda generación. Revista Nueva Sociedad, v. 160, n. 160, p. 101-117, 1999.

DE LA CRUZ, Rafael; PINEDA, Carlos; PÖSCHL, Caroline (Ed.). La alternativa local. Washington: BID, 2010.

DELAMAZA, Gonzalo; CUNILL, Nuria; JOIGNANT, Alfredo. Nueva agenda de descentralización en Chile. Santiago: Universidad de los Lagos-Ril, 2012.

DIMAGGIO, Paul J.; POWELL, Walter W. The iron cage revisited: institutional isomorphism and collective rationality in organizational fields. American Sociological Review, v. 48, n. 2, p. 147-160, 1983.

DURSTON, John. Clientelismo político y actores populares en tres regiones de Chile. En: DELAMAZA, Gonzalo et al. Nueva agenda de descentralización en Chile. Santiago: Universidad de los Lagos-Ril, 2012. p. 369-391.

EDELENEBOS, J. Institutional implications of interactive governance: insights from dutch practice. Governance: An International Journal of Policy, Administration, and Institutions, v. 18, n. 1, p. 111134, 2005.

FAO. Descentralización e impuesto predial local. Roma: FAO, 2004.

FONTRA. El poder de la transparencia. Montevideo: BID-ICD, 2012.

GANDHI, Jennifer. Political institutions under dictatorships. Nova York: Cambridge, 2008.

GANDHI, Jennifer; PRZEWORSKI, Adam. Cooperation, cooptation and rebellion under dictatorships. Economics and politics, v. 18, n. 4, p. 1-26, 2006.

GARGARELLA, Roberto; ARBALLO, Gustavo. Federalism and fiscal federalism: the emergence and distortion of the centro-federalist constitucional model. En: BROSIO, Giorgio; JIMÉNEZ, Juan Pablo. Decentralization and reform in Latin America. Cheltenham, UK: Cepal (Ecla)-GIZ, 2012. p. 13-37.

GERSCHEWSKI, Johannes. The three pillars of stability: towards an explanation of the durability of autocratic regimes in East Asia. Berlim: WZB, 2010.

GÓNGORA, Mario. Ensayo histórico sobre la noción de Estado en Chile en los siglos XIX y XX. Santiago: Ediciones de la Ciudad, 1981.

GUTAFSSON, Maria-Therese. Inclusión o cooptación de comunidades indígenas en la política local. Reflexiones desde los Andes peruanos. Revista Amérique Latine Histoire et Mémoire, ALHIM, n. 16, p. 27-48, 2008.

HALDENWANG, Christian von. Hacia un concepto politológico de la descentralización del Estado en América Latina. Revista Latinoamericana de Estudios Urbano-Regionales Eure, v. 16, n. 50, p. 61-77, 1990.

HART, Roger. La participación de los niños: de una participación simbólica a una participación auténtica. Ensayos Innocenti, n. 4, 1993. 
HOOD, Christopher. The new public management in the 1980s: variations on a theme. Accounting, Organization and Society, v. 20, n. 2/3, p. 93-109. 1995.

HOX, Joop; DE JONG-GIEVELD, Jenny. Operationalization and research strategy. Amsterdam: Swets \& Zeitilnger, 1990.

KICKERT, Walter. Public governance in the Netherlands: an alternative to anglo-american 'managerialism'. Public Administration, v. 75, n. 12, p. 731-752, 1997.

LANDELL-MILLS, Pierre. Citizens againts corruption. Londres: PTF, 2013.

MARCEL, Mario. Modelos alternativos de descentralización y la experiencia chilena. Santiago: Cieplan, 2008.

MARCH, James; OLSEN, Johan. Ambiguity and choice in organizations. Bergen, Norway: Universitetsforlaget, 1976.

MARCH, James; OLSEN, Johan. The new institutionalism: organizational factors in political life. American Political science Review, v. 78, n. 3, p. 734-749, 1984.

MASCAREÑO, Carlos. Descentralización y democracia en América Latina: ¿Una relación directa?: Elementos conceptuales para su estudio. Maryland: Latin American Studies Center University of Maryland, College Park, 2008.

MCKINSEY GLOBAL INSTITUTE. Construyendo ciudades competitivas: la clave para el crecimiento de América Latina, Washington DC. Disponible en: <www.mckinsey.com/search.aspx?q=Construyendo+ciudades+competitivas > . Acceso en: 15 jul. 2011.

MILLS, Edwin S. An aggregative model of resource allocation in a metropolitan area. American Economic Review Papers and Proceedings, v. 57, n. 2, p. 197-210, 1967.

MONTECINOS, Egon. Descentralización y democracia en Chile: análisis sobre la participación ciudadana en el presupuesto participativo y el plan de desarrollo comunal. Revista de Ciencia Política, v. 26, n. 2, p. 191-208, 2006.

MORENO, Luzón J. Teoría del clientelismo y estudio de la política caciquil. Revista de Estudios Políticos, v. 89, p. 191-224, 1995.

MORICONI, Marcelo. El malestar social y la víctima-cómplice. Revista Polis, v. 1, n. 5, p. 115-142, 2009.

NORTH, Douglass. Instituciones, cambio institucional y crecimiento económico. México, D.F: Fondo de Cultura Económica, 1993.

O'DONNELL, Guillermo. Algunas reflexiones acerca de la democracia, el Estado y sus múltiples caras. Revista del Clad, v. 42, p. 2-14, 2008.

OSZLAK, Oscar. Estado y sociedad: las nuevas reglas del juego. Buenos Aires: UBA, 1997.

PENAGLIA, Francesco. La paradoja del poder: ¿elitización o empoderamiento colectivo? Revista Polis, v. 11, n. 32, p. 105-118, 2011. "Deliberación Técnica y Movimiento”. 
PENAGLIA, Francesco; VALENZUELA, Esteban. Rebeldía en Calama: desafío al orden centralista chileno en un contexto de boom minero. Revista Mexicana de Ciencias Políticas y Sociales Unam, v. LIX, n. 222, p. 161-185, sept./dic. 2014.

PNUD. Informe regional 2013-2014. Nova York: Pnud, 2013.

RAVE, Gabriel. Compendio de actuaciones administrativas y derecho procesal administrativo. Medellín: Señal, 2003.

REPETTO, Julio Cesar. El Estado reformado, la nueva cuestión social y la gestión local. En: CONGRESO INTERNACIONAL DEL CLAD SOBRE LA REFORMA DEL ESTADO Y DE LA ADMINISTRACIÓN PÚBLICA, V, 2000, Santo Domingo, Rep. Dominicana.

ROSALES, Mario. Descentralización del Estado y finanzas municipales en América Latina. Santiago: Flacma, 2012.

SCHRÖTER, Bárbara. Clientelismo político: ¿existe el fantasma y cómo se viste? Revista mexicana de sociología, v. 72, n. 1, p. 141-175, 2010.

SELZNICK, Philip. Bases de la teoría de la organización. En: BALLART, Xavier; RAMIÓ, Carles. Teoría de la organización. v. 1. Madrid: Ministerio para las Administraciones Públicas, 1993. p. 195-212.

SEPÚLVEDA, Cristian; MARTÍNEZ-VÁSQUEZ, Jorge. Explaining property tax collections in developing countries: the case of Latin America. En: BROSIO, Giorgio; JIMÉNEZ, Juan Pablo. Decentralization and reform in Latin America. Cheltenham, UK: Cepal (Ecla)-GIZ, 2012. p. 172-221.

STEFES, Cristopher. Understanding post soviet transitions. Corruption, collusion and clientelism. Londres: Basinstoke, 2006.

STÖHR, Walter. El desarrollo regional en América Latina. Buenos Aires: Siap, 1972.

TOCQUEVILLE, Alexis. La democracia en América. México: Fondo de Cultura Económica, 2011.

VALENZUELA, Arturo. Political brokers in Chile: local government in a centralized polity. Durham, EUA: Duke, 1977.

VALENZUELA, Esteban. Adiós al municipio. Una red de gobierno local. Proposiciones-Sur, v. 28, p. 260-271, 1998.

VALENZUELA, Esteban. Chile duro: presicracia centralista impuesta por la dictadura derechista y administrada por la centroizquierda paternalista. En: CARRIÓN, Fernando. Descentralización en Ecuador: opciones comparadas. Quito: Flacso, 2007a. p. 119-142.

VALENZUELA, Esteban. Demoreal: un esquema de democracia real local. En: DE LA FUENTE, Gloria; MLYNARZ, Danae. El pueblo unidad... Mitos y realidades sobre la participación ciudadana en Chile. Santiago: U. Alberto Hurtado, 2013a. p. 93-110.

VALENZUELA, Esteban. Poder local apropiado. Santiago: Universidad Autónoma. 2007b.

VALENZUELA, Esteban. Rancagua: la fecundidad del gobierno local. Buenos Aires: Fundación Ebert, 1996. 
VALENZUELA, Esteban. Sistemas de petición de cuentas en Chile y propuestas para Colombia. Bogotá: GTZ, 2005.

VAN HELDEN, Jan; TER BOGT, Henk. The application of businesslike planning and control in local government: a field study of eight dutch municipalities. Local Government Studies, v. 27, n. 1, p. 61-86, 2001.

VÉLIZ, Claudio. La tradición centralista de América Latina. Barcelona: Ariel, 1984.

VEREDAS MUÑOZ, Sonia. Las asociaciones de inmigrantes en España. Práctica clientelar y cooptación política. Revista Internacional de Sociología, v. 61, n. 36, p. 207-225, 2003.

VILLALOBOS, Sergio. Portales: una falsificación histórica. Santiago: Andrés Bello, 1989.

WEBER, Max. Economía y sociedad. Habana: Inst. del Libro, 1971.

WINTROBE, Ronald. The political economy of dictatorship. Nova York: Cambridge University Press, 1988.

ZIBECHI, Raúl. Progresismo: la domesticación de los conflictos sociales. Santiago: Quimantú, 2010.

ZICCARDI, Alicia. Pobreza, desigualdad social y ciudadanía. Los límites de la política social en América Latina. Buenos Aires: Clacso, 2001.

Esteban Valenzuela es magíster en ciencia política - Universidad Católica de Chile. Máster en desarrollo — Universidad de Wisconsin, Estados Unidos. Doctor en historia contemporánea — Universidad de Valencia, España. Director del Departamento de Ciencia Política y Relaciones Internacionales. Universidad Alberto Hurtado. E-mail: evalenzu@uahurtado.cl.

Fabián Pressacco es licenciado en ciencia política - Universidad Católica de Córdoba, Argentina. Magíster en ciencias sociales - Universidad Alberto Hurtado (Ilades). Doctor en sociología y ciencia política - Universidad de Deusto, España. Profesor del Departamento de Ciencia Política y Relaciones Internacionales. Universidad Alberto Hurtado. E-mail: fpressac@uahurtado.cl.

Ignacio Cienfuegos es administrador público de la Universidad de Chile. Magister en gerencia y políticas públicas Universidad Adolfo Ibáñez. Doctor (PhD) por la Universiteit Twente, Holanda. Profesor del Departamento de Ciencia Política y Relaciones Internacionales. Universidad Alberto Hurtado. E-mail: icienfuego@uahurtado.cl.

Francesco Penaglia es administrador público - Universidad de Santiago. Magister en estudios sociales y políticos latinoamericanos - Universidad Alberto Hurtado. Profesor del Departamento de Ciencia Política y Relaciones Internacionales. Universidad Alberto Hurtado. E-mail: fpenaglia@uahurtado.cl. 